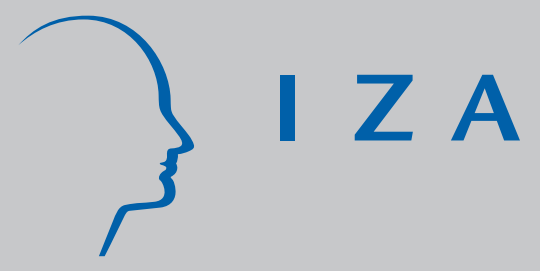

IZA DP No. 856

Management Incentives, Signaling Effects and the Costs of Vertical Integration

Dirk Sliwka

August 2003 


\title{
Management Incentives, Signaling Effects and the Costs of Vertical Integration
}

\author{
Dirk Sliwka \\ University of Bonn and IZA Bonn \\ Discussion Paper No. 856 \\ August 2003
}

\author{
IZA \\ P.O. Box 7240 \\ D-53072 Bonn \\ Germany \\ Tel.: +49-228-3894-0 \\ Fax: +49-228-3894-210 \\ Email: iza@iza.org
}

This Discussion Paper is issued within the framework of IZA's research area Mobility and Flexibility of Labor. Any opinions expressed here are those of the author(s) and not those of the institute. Research disseminated by IZA may include views on policy, but the institute itself takes no institutional policy positions.

The Institute for the Study of Labor (IZA) in Bonn is a local and virtual international research center and a place of communication between science, politics and business. IZA is an independent, nonprofit limited liability company (Gesellschaft mit beschränkter Haftung) supported by Deutsche Post World Net. The center is associated with the University of Bonn and offers a stimulating research environment through its research networks, research support, and visitors and doctoral programs. IZA engages in (i) original and internationally competitive research in all fields of labor economics, (ii) development of policy concepts, and (iii) dissemination of research results and concepts to the interested public. The current research program deals with (1) mobility and flexibility of labor, (2) internationalization of labor markets, (3) welfare state and labor market, (4) labor markets in transition countries, (5) the future of labor, (6) evaluation of labor market policies and projects and (7) general labor economics.

IZA Discussion Papers often represent preliminary work and are circulated to encourage discussion. Citation of such a paper should account for its provisional character. A revised version may be available on the IZA website (www.iza.org) or directly from the author. 
IZA Discussion Paper No. 856

August 2003

\section{ABSTRACT}

\section{Management Incentives, Signaling Effects and the Costs of Vertical Integration}

The costs of vertical integration are analyzed within a game-theoretic signaling model. It is shown that a company when being vertically integrated with a supplier may well decide to buy certain components from this supplier even at a lower quality than that offered by external sources. When the parent company decides to stop buying components from the integrated supplier, the value of the ownership share in the supplier is reduced: On the one hand, the supplier's profit from the transactions with its parent is foregone. But on the other hand, other clients may decide against buying from this supplier as the latter's reputation for providing an appropriate quality is damaged. The loss in value of the ownership share may outweigh the loss due to the lower quality. The anticipation of this effect leads to reduced ex ante incentives for the supplier's management to raise quality. A spin-off may therefore be beneficial as it strengthens incentives. Costs and benefits of vertical integration are analyzed and consequences for vertically integrated companies organized in profit centers are discussed.

JEL Classification: $\quad$ C22, L22, M55

Keywords: vertical integration, incentives, outsourcing, signaling

Dirk Sliwka

Betriebswirtschaftliche Abteilung II

University of Bonn

Adenauerallee 24-42

53113 Bonn

Germany

Tel.: +49 228739214

Fax: +49 228739210

Email: dirk.sliwka@uni-bonn.de 


\section{A Introduction}

In his influential article Coase (1937) posed the key question for the theory of the firm: "Why is not all production carried on by one big firm?" He developed an idea, which has later been described by Williamson (1985) with the term selective intervention: A firm that is integrated in such a manner should be able to imitate the market and intervene selectively only if market transactions are inefficient. Integration therefore should dominate market transactions in any case. As apparently this is not the case, there must be costs of integration, which exceed the costs of market exchange in many instances. The non-integration of a supplier with a client, for instance, will therefore be preferred if the so called transaction costs of processing a transaction within a firm are higher than the transaction costs of market exchange.

Typically it is very hard to grasp precisely what those transaction costs are and how they are determined in different contexts. We therefore focus in this paper on calling attention to one very specific type of transaction costs arising in the context of vertical integration. In the model presented here, we analyze the situation of a firm, in which a supplier is vertically integrated with its client, such that the client owns a significant part of the supplier. A key assumption we make is that the parent company (the client) has superior knowledge about the quality of products produced by its own supplier than potential other clients of this supplier. This superior knowledge might be due to the fact that vertical integration leads to much more possibilities to gain information on the products of the supplier. It may also be simply justified by the fact that the parent company is in practice typically also the most important client of the supplier and therefore has superior knowledge just on the basis of previous experience with the supplier's products.

But due to this superior knowledge the parent company's decision to switch the supplier for instance by supplying an input no longer from the integrated supplier but from a different source has a strong signaling effect on the outside market. This may be illustrated by an example: General Motors (GM) supplies a large part of its automotive components from Delphi, the worlds largest automotive supplier which had been owned by GM until 1999. ${ }^{1}$ Consider now a situation in which GM decides to buy a certain important component no longer from Delphi, but from some other independent supplier, as GM's managers think that this supplier rather than Delphi is able to produce this component at a sufficiently high quality. As GM itself is Delphi's most important client ${ }^{2}$ and therefore should also be best informed on the quality of 
components made by Delphi, other car manufacturers may be led by this decision to stop placing new procurement contracts with Delphi for those component types. Hence, the loss of an order from GM may lead to a chain reaction in which Delphi may lose other clients as well. The procurement decision of the parent company therefore has an indirect effect on the value of its stake in the supplier. This loss in value due to a reduced quality reputation of the supplier may therefore outweigh potential losses from inferior quality.

But it is important to note that this effect leads to weakened incentives for the management of the in-house supplier. Even with lower product quality, it may be possible for this supplier to maintain a certain market share by selling to the parent company. The pressure on management to exert effort to improve product quality decreases. Such a pressure to supply an appropriate quality should be much stronger for an independent supplier. This could have been one reason for the spin-off of Delphi by GM. Indeed analysts have argued in this case that a spin-off serves to "create stronger competition among suppliers". 3

There is of course the question why an integrated firm is not able to induce a similar market pressure on the in-house supplier, if this leads to a higher overall corporate value. The simple and stylized model presented here gives the following answer: As viewed from an ex-ante perspective it is beneficial to buy an input from the integrated supplier if the quality is better than that offered by competitors in expected terms. Otherwise the management of the supplier will not have appropriate incentives to raise product quality. If however, it has turned out that the supplier is not able to produce high quality products, then it can be beneficial for the parent company ex-post for the mentioned reasons not to switch to a different supplier. The threat of switching the supplier may therefore not be credible. A spin-off or de-merger can make such a threat credible.

The most far-reaching microeconomic attempt to explain the costs and benefits of vertical integration is the incomplete contracts approach. ${ }^{4}$ The allocation of property rights as residual rights of control determines the allocation of bargaining power in situations, for which there are no prespecified contractual arrangements, and therefore determines also the incentives for relationship specific investments by the involved agents. Costs of vertical integration arise by the fact that the supplier looses control rights and therefore has weaker investment incentives. ${ }^{5}$ In this paper we also impose a strong form of contractual incompleteness: The decision whether and at what terms 
to supply a good is not contractible ex-ante. Furthermore, in contrast to the standard Grossman-Hart type framework, here the bargaining problem will be simplified extremely. Yet, the basic assumption is that the decision to do business with the supplier creates rents on the side of the buyer as well as the supplier. To keep the modelling simple we intentionally analyze a certain predetermined game in which we compare given institutional arrangements and we do not seek for optimal contracts. But we model explicitly a situation of asymmetric information, in which the procurement decision of a parent company has indirect effects on the value of its stake in a supplier. The reason for the costs of vertical integration is in this case the fact that the management of the supplier may earn rents even after exerting a low effort and hence a realization of a lower input quality.

A branch of the literature on industrial economics has also analyzed vertical structures with the main focus on examining restraints imposed by the supplier on the pricing behavior and quantity choice of retailers. In those models typically there are no costs of integration as an integrated structure always acts jointly profit maximizing. The main focus is then to check whether this jointly optimal behavior can also attained in a disintegrated structure by vertical restraints appropriately chosen by the supplier (see for instance Tirole (1988), Chapter 4 or for a more recent overview from a contract theoretical perspective Schmitz and Rosenkranz (2001)).

This paper is structured as follows: In the subsequent section the model is introduced. In Section $\mathrm{C}$ the model will be analyzed without the incentive problem for the management of the supplier. The following Section D examines the case in which the management of the supplier can exert effort to raise the quality of the input good. In Section E the optimal size of the parent's stake in the supplier will be determined. Practical implications for the integration decision as well as the management of decentralized profit centers will be discussed in the concluding section F.

\section{B The Model}

In what follows a game is analyzed to clarify the above mentioned effects. We consider a situation, in which a parent company $U_{1}$ holds a share $\lambda$ in a supplier $S$. If $\lambda$ is equal to 1 , the supplier is fully integrated. If $\lambda$ is zero the supplier is independent. First, we assume that $\lambda$ is exogenously given. As a starting point we therefore investigate the situation of firm that is vertically integrated in predetermined way and analyze the 


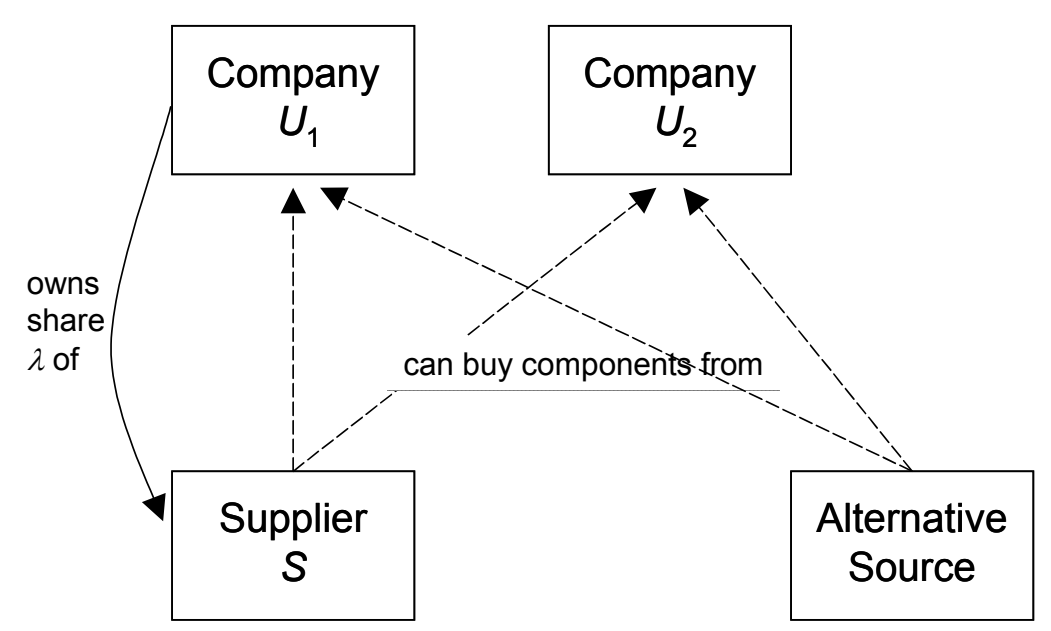

Figure 1: The organizational structure of the supply chain

consequences.

The supplier produces an input, which is needed by $U_{1}$ as well as a second client $U_{2}$ at a given fixed quantity. ${ }^{6}$ Both companies have the option to acquire the input from an alternative source on the market. The organisational structure is illustrated in Figure 1.All parties are assumed to be risk neutral. At stage 1 the parent company $U_{1}$ observes the quality of the components produced by the supplier $S .^{7}$ The quality can take two values: Either a high quality $q_{H}$ or a low quality $q_{L}$ is realized. The prior distribution is such that $S$ produces a high quality with probability $\tau$ :

$$
q= \begin{cases}q_{H} & \text { with probability } \tau \\ q_{L} & \text { with probability } 1-\tau\end{cases}
$$

In the beginning we assume that $\tau$ is exogenously given. Later we will endogenize $\tau$ such that it depends on an effort choice by the supplier's management. The realized quality $q$ is not observed by the other client $U_{2}$. First, company $U_{1}$ can decide, whether to buy the product from its own supplier $S$ or on the outside market. The expected quality of a product supplied on the market is $q_{M}$. We assume that $q_{L}<q_{M}<q_{H}$. Hence, it is possible that $S$ supplies a higher or a lower quality than its competitors. Company $U_{1}$ 's procurement decision is denoted by $x_{1} \in\{0,1\}$, where $x_{1}=1$ if the product is supplied from $S$ and $x_{1}=0$ if it is bought on the market.

The parent company's profit depends on the quality of the input good. Company 
$U_{1}$ 's profit when buying from its own supplier is

$$
R_{1}(q)= \begin{cases}R_{1 H} & \text { when } q=q_{H} \\ R_{1 L} & \text { when } q=q_{L}\end{cases}
$$

where $R_{1 H}>R_{1 L}$. The parent company $U_{1}$ 's profit when buying on the market is $R_{1 M}$. Analogously, the supplier's profit when trading with its parent company is

$$
\Pi_{1}(q)= \begin{cases}\Pi_{1 H} & \text { when } q=q_{H} \\ \Pi_{1 L} & \text { when } q=q_{L}\end{cases}
$$

with $\Pi_{1 H} \geq \Pi_{1 L}$. Note, that although a possible bargaining process among supplier and buyer is therefore not explicitly modelled, this formulation encompasses the possibility that the supplier earns a higher rent from trading with its parent company when he is able to offer a high quality.

Although being not able to observe the quality directly, the second potential client $U_{2}$ observes the procurement decision $x_{1}$ by $U_{1}$ and makes himself a decision $x_{2}$. If $x_{2}=1$ company $U_{2}$ buys the product from $S$, if $x_{2}=0$ he buys on the market with expected quality $q_{M}$. Company $U_{2}$ 's final profit when trading with $S$ is denoted by

$$
R_{2}(q)= \begin{cases}R_{2 H} & \text { when } q=q_{H} \\ R_{2 L} & \text { when } q=q_{L}\end{cases}
$$

with $R_{2 H}>R_{2 L}$. Note that this profit is learned only after the trade took place. If client $U_{2}$ bought on the market instead, its payoff from this trade is $R_{2 M}$. To simplify the analysis we assume that $R_{1 M}=R_{2 M}=R_{M}$. The supplier $S$ 's profit when trading with $U_{2}$ is assumed to be always $\Pi_{2} .{ }^{8}$ The realized quality in both trades is unverfiable and no contracts can be written specifiying the trading decisions.

The supplier's total profit for given procurement decisions $x_{1}$ and $x_{2}$ is therefore

$$
x_{1} \Pi_{1}(q)+x_{2} \Pi_{2} .
$$

The parent company $U_{1}$ 's total profit in turn consists of the direct profit as a function of the quality of the input good and the procurement decision $x_{1}$ as well as the value of share of holding in $S$ :

$$
x_{1} R_{1}(q)+\left(1-x_{1}\right) R_{M}+\lambda\left(x_{1} \Pi_{1}(q)+x_{2} \Pi_{2}\right) .
$$


Finally the second client $U_{2}$ 's profit is $x_{2} R_{2}(q)+\left(1-x_{2}\right) R_{M}$.

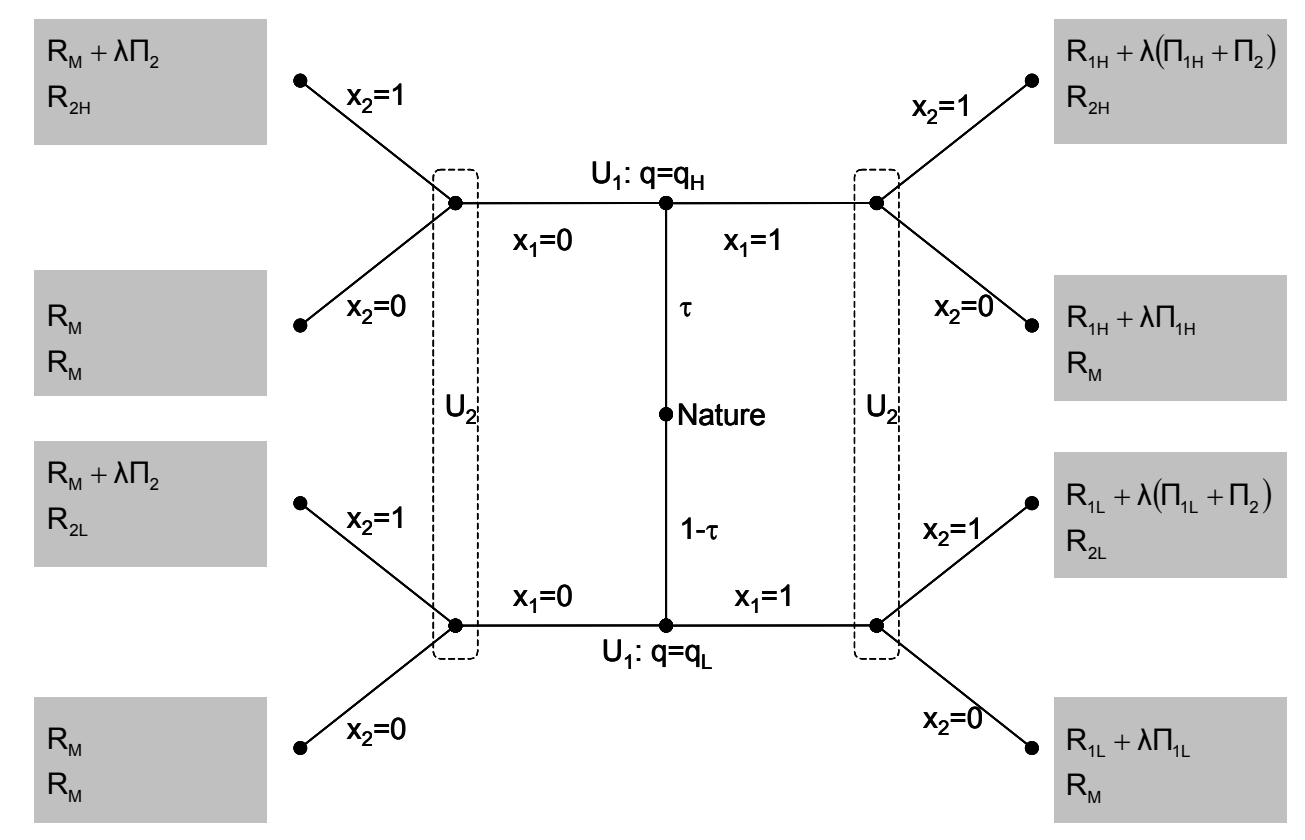

Figure 2: The game tree

The structure of the game is described by the game tree in Figure 2. The game is a signaling game and we now seek perfect Bayesian Equilibria. To consider only the interesting cases where $U_{1}$ 's decision affects $U_{2}$ 's choice we impose the following additional assumption:

Assumption 1: The direct surplus earned by $U_{1}$ and $U_{2}$ each when trading with $S$ is higher than their respective surplus when buying the input good on the market if and only if the quality produced by $S$ is high, i.e.

$$
\begin{aligned}
& R_{1 H}>R_{M}>R_{1 L} \text { and } \\
& R_{2 H}>R_{M}>R_{2 L} .
\end{aligned}
$$

Hence, the input can be bought on the market at an intermediate quality and the surplus earned by $U_{1}$ and $U_{2}$ is strictly increasing in the quality of the input. Without any asymmetric information it is therefore always beneficial for both companies to buy the good from supplier $S$ only at a high quality, when the potential impact on the value 
of $U_{1}$ 's share is not taken into account. If Assumption 1 is not satisfied the decision problem is trivial, as the input good will either be always or never bought from $S$.

\section{The Procurement Decision as a Signal}

As described above, company $U_{2}$ may receive information on the true quality of the input good produced by $S$ from the parent company's procurement decision. If $U_{1}$ buys the input from its own supplier $S$ this might give a positive signal on product quality. But if this always leads the other client also to buy the good from the supplier $S$, then the parent company $U_{1}$ may have an interest to buy the good from its own supplier even at the low quality: The reason is that it may anticipate that the value of its ownership share in the supplier increases, when also the second client buys the good from $S$. This effect may outweigh the direct loss due to the use of an input of low quality.

A perfect Bayesian Equilibrium of the game described above consists of

- the parent company $U_{1}$ 's strategy denoted by the probability $\alpha_{H}\left(\alpha_{L}\right)$, with which $U_{1}$ buys from $S$, i.e. chooses $x_{1}=1$, when it observes quality $q_{H}\left(q_{L}\right)$,

- a posterior probability $\widehat{\tau}_{x_{1}}$ for the realization of the high quality describing the beliefs of company $U_{2}$ after observing the decision $x_{1}$ made by $U_{1}$, and

- client $U_{2}$ 's strategy denoted by the probability $\beta_{x_{1}}$ of buying the product from $S$ after having observed the decision $x_{1}$ made by $U_{1}$.

It seems quite intuitive that company $U_{1}$ should always buy the input product from $S$, if $S$ offers a high quality. Indeed we can show, that this will always be the case given a simple 'refinement' which imposes a plausible condition on out-of-equilibrium beliefs: ${ }^{9}$

Condition (Monotonicity of beliefs): When $x_{1}=1$ is off the equilibrium path, then out-of-equilibrium beliefs are such that $\hat{\tau}_{1}>\hat{\tau}_{0}$.

The equilibrium concept itself does not place restrictions on client $U_{2}$ 's beliefs off the equilibrium path. The given condition now simply states that when $U_{2}$ observed that $U_{1}$ has bought the input from $S$ off the equilibrium path (i.e. when $\alpha_{H}=\alpha_{L}=0$ 
such that $U_{1}$ never buys from $S$ in equilibrium), then this should raise the subjective probability with which $U_{2}$ believes that the input is of high quality. Using this condition we can show the following: ${ }^{10}$

Lemma 1 With monotonic beliefs (i) the parent company $U_{1}$ always buys from $S$ after observing the high quality. (ii) Client $U_{2}$ will never buy from $S$ if $U_{1}$ has not bought from $S$.

Proof: See Appendix.

Hence, we can also exclude any equilibria in which $U_{2}$ buys the good from $S$ after $U_{1}$ not bought the good from its own supplier: In this case it always learns that the quality must be low. Hence, if $U_{1}$ does not buy the good from $S$ then $U_{2}$ will neither do that.

After observing that the parent company has bought from $S$, the other client $U_{2}$ cannot be certain that the quality is high as $U_{1}$ may be tempted to buy from $S$ also at the low quality. By using Bayes' Rule it will, however conclude, that

$$
\begin{aligned}
\widehat{\tau}_{1} & =\operatorname{Pr}\left\{q=q_{H} \mid x_{1}=1\right\}=\frac{\operatorname{Pr}\left\{q=q_{H} ; x_{1}=1\right\}}{\operatorname{Pr}\left\{x_{1}=1\right\}} \\
& =\frac{\tau}{\tau+(1-\tau) \alpha_{L}} .
\end{aligned}
$$

If the parent company never buys the good from $S$ if the quality is low, i.e. if $\alpha_{L}=0$, then its private information is fully revealed, that is $\widehat{\tau}_{1}=1$. This is the case of a separating equilibrium. No distortion exists and both buy from $S$ only if the quality is indeed high.

But if the parent company buys from $S$ whatever the quality offered $\left(\alpha_{L}=1\right)$, then nothing can be learned from its procurement decision about the quality offered by $S$; the posterior probability for a high quality $\widehat{\tau}_{1}$ coincides with the prior probability $\tau$. The equilibrium is a pooling equilibrium.

Two factors turn out to be essential when analyzing what kind of equilibrium arises in which circumstances: On the one hand, company $U_{2}$ 's optimal behavior is important when it does not learn anything about the quality from the parent company's decision. Its expected profit when trading with $S$ in this case is $E\left[R_{2} \mid \tau\right]$. If, however, the good 
is bought on the market its profit is $R_{M}$. Hence, if

$$
R_{M}<E\left[R_{2} \mid \tau\right],
$$

then $U_{2}$ will always buy the good from $S$ if it receives no additional information on product quality. Otherwise it will never buy from $S$ without further information.

On the other hand, it is important to look at the parent company's decision when anticipating a certain reaction by the other client $U_{2}$ given that $q=q_{L}$. If buying from $S$ leads $U_{2}$ also to buy from $S$, then the parent company has to weigh the quality loss due to a bad input against a higher value of the ownership share in $S$. When trading with $S$ it earns a direct profit $R_{1 L}$. The value of the ownership share is $\lambda\left(\Pi_{1 L}+\Pi_{2}\right)$ in that case. When sourcing on the market, a larger direct profit $R_{M}$ is attained. However, the ownership share looses all value, as in turn $U_{2}$ also buys from one of $S$ 's competitors. Hence, company $U_{1}$ chooses inhouse procurement when $q=q_{H}$, if

$$
R_{1 L}+\lambda\left(\Pi_{1 L}+\Pi_{2}\right)>R_{M} .
$$

If, however, $U_{1}$ knows that its own decision to buy from $S$ does not lead $U_{2}$ to do the same, it will still buy at the low quality if the following stricter condition holds:

$$
R_{1 L}+\lambda \Pi_{1 L}>R_{M} .
$$

In the following sequence of results the equilibria for different parameter constellations are characterized. The results are proved in the appendix of this paper.

Proposition 1 If $U_{1}$ 's ownership share in $S$ is larger than a cut-off value $\lambda_{L}$ and if the ex-ante expected quality of inputs produced by $S$ exceeds market quality (i.e. $R_{M}<E\left[R_{2} \mid \tau\right]$, then there is a unique pooling equilibrium, in which $U_{1}$ buys from $S$ regardless of the quality and $U_{2}$ always follows this decision. The cut-off value for the ownership share $\lambda_{L}$ is given by

$$
\lambda_{L}=\frac{R_{M}-R_{1 L}}{\Pi_{1 L}+\Pi_{2}} .
$$

If $U_{1}$ buys the input from $S$ regardless of its quality, then $U_{2}$ can learn nothing from its decision. If $E\left[R_{2} \mid \tau\right]>R_{M}$, then $U_{2}$ 's expected profit when buying from $S$ is still higher than its profit when buying on the market. Client $U_{2}$ will then always buy the 
input from $S$.

Company $U_{1}$ 's procurement strategy is indeed optimal, if its ownership share in $S$ is sufficiently large. On the one hand, its direct profit is lower when buying from $S$ at the low quality compared to the outside market but the value of the ownership share is higher. If the share $\lambda$ is sufficiently large the latter effect dominates the former. This is exactly the case, when inequality (4) is fulfilled, which is equivalent to $\lambda \geq \lambda_{L}$. Note that $\lambda_{L}$ may well exceed 1 in certain parameter constellations. In those cases no such pooling equilibrium exists.

The value of the ownership share increases for two reasons: First, the parent company directly benefits from the supplier's surplus from the internal trade. But in addition, the parent company's positive procurement decision is followed by the other client and the parent company earns a share $\lambda$ of the surplus generated from this external transaction. In this case vertical integration, if sufficiently strong, creates an advantage from 'opaqueness': The parent company's private information on the quality is not revealed, and this raises the value of the ownership share and the total value of the integrated firm.

If, however, client $U_{2}$ 's expected profit without further information on the quality is lower than its profit when buying on the market $\left(E\left[R_{2} \mid \tau\right]<R_{M}\right)$, then the mentioned behavior cannot occur in equilibrium as the other client will of course never buy the input from $S$, when he learns nothing about the quality. It remains to check, whether the parent company will still have an interest in those cases, to buy from $S$ even at the low quality. This is indeed the case if the ownership share $\lambda$ is sufficiently large, as shown in the following result:

Proposition 2 If the parent company $U_{1}$ 's ownership share in $S$ is larger than a certain cut-off value $\lambda_{H}$ (where $\lambda_{H}>\lambda_{L}$ ) and if the ex-ante expected quality of the input produced by $S$ is lower than market quality $\left(R_{M}>E\left[R_{2} \mid \tau\right]\right)$, then there is a unique pooling equilibrium, in which the parent company $U_{1}$ buys the product from $S$ independent of its quality and $U_{2}$ never buys the product from $S$. The cut-off value for the ownership share $\lambda_{H}$ is given by

$$
\lambda_{H}=\frac{R_{M}-R_{1 L}}{\Pi_{1 L}} .
$$

Note that the cut-off value $\lambda_{H}$ for the ownership share is higher than the cut-off $\lambda_{L}$ 
given in Proposition 1. This cut-off value $\lambda_{H}$ follows from condition (5). Here, the parent company's decision to buy from $S$ does not lead $U_{2}$ to follow. The 'opaqueness' advantage of integration does not exist. The only reason to procure in-house is that the parent company benefits from its share in the suppliers profits from the internal trade $\Pi_{1 L} \cdot{ }^{11}$ If $\lambda$ is smaller than $\lambda_{H}$ then this benefit is not high enough to outweigh the loss due to an input of lower quality. If it is larger than $\lambda_{H}$, then in-house procurement is beneficial. Note, that this will never be the case if $R_{1 L}+\Pi_{1 L}<R_{M}$. If this condition holds it will never be worthwhile to buy internally at the low quality - even with a fully integrated supplier $(\lambda=1)$.

If the ownership share $\lambda$ is even lower than the cut-off value $\lambda_{L}$ from Proposition 1 , then the quality loss outweighs the benefit from a higher corporate value of $S$ in any case - that is even when the decision to buy from $S$ leads $U_{2}$ to follow. In this case the parent company will always reveal its information about the quality truthfully via its procurement decision. This is shown in the following result:

Proposition 3 If the parent company's ownership share in $S$ is lower than the cutoff value $\lambda_{L}$, then there exists a unique separating equilibrium, in which the parent company buys from $S$ only at the high quality. In this case client $U_{2}$ buys from $S$ if and only if $U_{1}$ has done this.

When the ownership share is sufficiently small the companies thus act as they would do with symmetric information.

Note that the decision of parameter constellations described so far has not been exhaustive. It remains to analyze situations in which on the one hand $R_{M}>E\left[R_{2} \mid \tau\right]$ - that is without information revelation it is always better for $U_{2}$ not to buy the input from $S-$ and on the other hand the ownership share $\lambda$ is between $\lambda_{L}$ and $\lambda_{H}$. If the parent company always buys from $S$, then the information will not be revealed and $U_{2}$ will not buy from $S$. But in this case the response by $U_{1}$ will be only to buy at the high quality as condition (5) is not met. Hence, there can be no equilibrium in which the parent company always buys from $S$ at the low quality in that case. If, however, it never buys from $S$ at the low quality, its information will be fully revealed. In that case the best response by $U_{2}$ will be always to follow $U_{1}$ 's decision. As condition (4) is met, $U_{1}$ indeed would then have an interest to buy from $S$ even at the low quality. This can neither be the case in equilibrium. Therefore, we cannot have a pure strategy 
equilibrium in this case. There are, however, semi-separating equilibria as shown in the following result:

Proposition 4 If the ex-ante expected quality of the input produced by $S$ is smaller than that offered on the market $\left(R_{M}>E\left[R_{2} \mid \tau\right]\right)$ and if the ownership share $\lambda \in$ $\left(\lambda_{L}, \lambda_{H}\right)$, then a unique semi-separating equilibrium exists. The parent company $U_{1}$ buys from $S$ when the quality is low with probability

$$
\alpha_{L}=\frac{\tau\left(R_{2 H}-R_{M}\right)}{(1-\tau)\left(R_{M}-R_{2 L}\right)}
$$

When observing that $U_{1}$ has bought from $S$ then $U_{2}$ will follow with probability

$$
\beta_{1}=\frac{R_{M}-R_{1 L}}{\lambda \Pi_{2}}-\frac{\Pi_{1 L}}{\Pi_{2}}
$$

Figure 3 shows these results. The profit with market procurement is plotted on the abscissa, the ownership share $\lambda$ on the ordinate axis. For very low values of $\lambda$ information will be fully revealed in a separating equilibrium. For higher values of $\lambda$ information may not be fully revealed. Pooling always takes place when the profit with market procurement $R_{M}$ is smaller than $U_{2}$ 's expected profit from trading with $S$ with no information on quality $E\left[R_{2} \mid \tau\right]$. If that is not the case, there will still be pooling, if the ownership share $\lambda$ is very large (i.e. above $\lambda_{H}$ ). In the former case, $U_{2}$ always follows $U_{1}$ 's decision. In the latter, the parent company buys from $S$ at the low quality even though $U_{2}$ never follows. Finally, there are semi-separating equilibria, when $R_{M}$ is larger than $E\left[R_{2} \mid \tau\right]$ and the ownership share $\lambda$ is between $\lambda_{L}$ and $\lambda_{H}$ which are the two upward sloping straight lines.

There are other equilibria as well, in which one party plays a mixed and the other one a pure strategy. Those are characterized in the appendix of this paper. Such equilibria arise in parameter constellations on the boundaries of the regions shown in 3 . In the interior of those regions equilibria are unique given the mentioned refinement. 


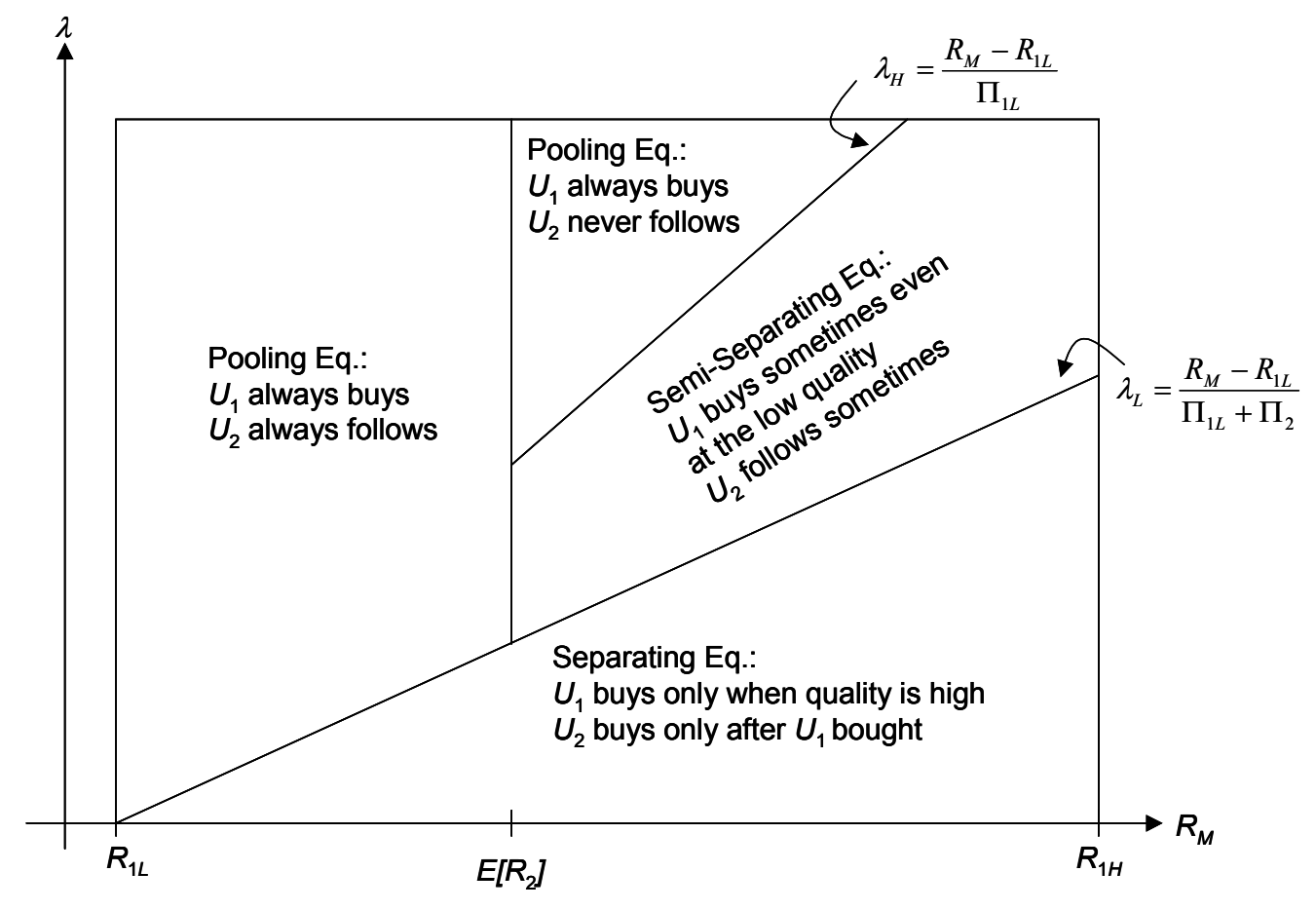

Figure 3: Perfect Bayesian Equilibria

\section{Management Incentives}

Now the model analyzed in the preceding section is extended, to investigate the impact of the described effects on the incentives of the supplier's management to raise the quality of the product produced by $S$. The intention is again not to search for optimal contracts but to analyze the impact of the ownership share $\lambda$ on management incentives. Note that so far, the supplier has not been represented as an active player in the game. We now introduce an initial stage 0 at which a manager $M$ of the supplier $S$ decides on his effort to raise the quality produced by $S$.

We assume that the manager $M$ can choose among two effort levels affecting the probability that a high quality is realized. For ease of notation the effort levels are directly denoted by the probability that the high quality is realized: A high effort corresponds to the probability $\tau_{H}$ for a realization of the high quality and a low effort to probability $\tau_{L}<\tau_{H}$. Depending on the effort level the manager has to bear private costs $c(\tau)$. For simplicity it is assumed that $c\left(\tau_{H}\right)=c$ with $c>0$ and $c\left(\tau_{L}\right)=0$. To analyze the effects of vertical integration on management incentives in a simple way, 
we assume that the manager's utility takes the form

$$
\mu \cdot \Pi_{S}-c(\tau)
$$

where $\Pi_{S}=x_{1} \Pi_{1}(q)+x_{2} \Pi_{2}$ is the supplier's profit and $\mu$ is an exogenously given constant. This may for instance be due to the fact that $M$ owns a fixed capital share in $S$ or has received stock options which are always 'in the money' in the considered range. The manager's effort is assumed to be unobservable by both $U_{1}$ and $U_{2}$.

The subsequent stages of the game are unaltered. Again the parent company observes the quality offered by $S$. The strategic situation for $U_{1}$ and $U_{2}$ has only changed in so far, as $U_{2}$ 's quality expectations depend upon the equilibrium effort exerted by $M$. The equilibrium profile is now only extended by manager $M$ 's effort choice and $U_{1}$ 's and $U_{2}$ 's beliefs on this effort choice which must be correct in equilibrium. ${ }^{12}$

For a given effort choice by $M$ the results derived above continue to hold with the only difference that $\tau$ is replaced either by $\tau_{L}$ or $\tau_{H}$. Hence, if for a given effort choice $\tau$ a certain equilibrium constellation arises in the signaling game between $U_{1}$ and $U_{2}$ as analyzed above and if $M$ 's best response to such an equilibrium constellation is indeed to choose $\tau$, then we have found a Perfect Bayesian Equilibrium of this new game.

Manager $M$ 's incentives depend of course on the equilibrium strategies by $U_{1}$ and $U_{2}$ described by $\alpha_{L}$ and $\beta_{1}$. When choosing the high effort level his expected utility is

$$
\mu\left(\tau_{H}\left(\Pi_{1 H}+\beta_{1} \Pi_{2}\right)+\left(1-\tau_{H}\right)\left(\alpha_{L}\left(\Pi_{1 L}+\beta_{1} \Pi_{2}\right)\right)\right)-c .
$$

With the low effort level it is

$$
\mu\left(\tau_{L}\left(\Pi_{1 H}+\beta_{1} \Pi_{2}\right)+\left(1-\tau_{L}\right)\left(\alpha_{L}\left(\Pi_{1 L}+\beta_{1} \Pi_{2}\right)\right)\right) .
$$

He will choose the high effort level $\tau_{H}$ if (6) is larger than (7) which is equivalent to

$$
\Pi_{1 H}+\beta_{1} \Pi_{2}-\alpha_{L}\left(\Pi_{1 L}+\beta_{1} \Pi_{2}\right) \geq \frac{c}{\mu\left(\tau_{H}-\tau_{L}\right)} .
$$

The left hand side attains the highest value if $\alpha_{L}=0$ and $\beta_{1}=1$, i.e. both companies buy from $S$ only at the high quality. In this case the manager's incentives will be strongest. If condition (8) were not met for $\alpha_{L}=0$ and $\beta_{1}=1$, there would never be an equilibrium in which the manager chooses a high effort level. Hence, we assume that this condition is always met: 
Assumption 2: If the parent company $U_{1}$ and the other client $U_{2}$ both buy from $S$ only at the high quality, manager $M$ will choose the high effort level:

$$
\Pi_{1 H}+\Pi_{2}>\frac{c}{\mu\left(\tau_{H}-\tau_{L}\right)}
$$

The left hand side of condition (8) attains the lowest possible value when $\alpha_{L}=1$, i.e. the parent company $U_{1}$ buys from $S$ whatever the quality offered. In that case incentives depend only on the potential surplus from the internal trade with the parent company as this surplus $\Pi_{1}(q)$ may depend upon quality. If condition (8) were met for $\alpha_{L}=1$ then it would be met in any equilibrium. Hence, we assume that the difference among $\Pi_{1 H}$ and $\Pi_{1 L}$ is not large enough, to make a high effort attractive in these cases:

Assumption 3: If the parent company $U_{1}$ buys from $S$ at both qualities, then exerting the high effort level is never optimal for the manager $M$ :

$$
\Pi_{1 H}-\Pi_{1 L}<\frac{c}{\left(\tau_{H}-\tau_{L}\right) \mu} .
$$

Whereas Assumption 2 defines the case of the strongest possible incentives, Assumption 3 deals with the weakest possible incentives for manager $M$. If one of both assumptions is not satisfied, the incentive problem would be trivial as the manager would either always or never choose the high effort level independent of the ownership structure.

What is now the effect of the ownership share $\lambda$ on the incentives of the supplier's management? For simplicity we focus only on cases where the manager chooses pure strategies and obtain the following result:

Proposition 5 The supplier's manager $M$ will always choose the low effort level only if $U_{1}$ 's ownership share $\lambda$ is either larger than $\lambda_{H}$, or $\lambda \in\left[\lambda_{L}, \lambda_{H}\right]$ and

$$
\lambda \geq \frac{\left(R_{M}-R_{1 L}\right)\left(R_{M}-E\left[R_{2} \mid \tau_{L}\right]\right)}{\left(1-\tau_{L}\right)\left(R_{M}-R_{2 L}\right)\left(\frac{c}{\mu\left(\tau_{H}-\tau_{L}\right)}-\left(\Pi_{1 H}-\Pi_{1 L}\right)\right)} .
$$


The manager will always choose the high effort level only if either $U_{1}$ 's ownership share $\lambda$ is either smaller than $\lambda_{L}$, or $\lambda \in\left[\lambda_{L}, \lambda_{H}\right]$ and

$$
\lambda \leq \frac{\left(R_{M}-R_{1 L}\right)\left(R_{M}-E\left[R_{2} \mid \tau_{H}\right]\right)}{\left(1-\tau_{H}\right)\left(R_{M}-R_{2 L}\right)\left(\frac{c}{\mu\left(\tau_{H}-\tau_{L}\right)}-\left(\Pi_{1 H}-\Pi_{1 L}\right)\right)} .
$$

Proof: See Appendix.

Hence, the supplier's manager exerts a high effort level only if the ownership share is sufficiently small. This result hints at an important element among the costs of vertical integration: There is less pressure on a vertically integrated supplier to produce a high quality than on an independent supplier. The management of an integrated supplier anticipates that its parent company may buy its products even at a low quality if its ownership share is sufficiently large. The reason is that the parent company fears a loss due to a reduced value of its stake in the supplier.

As described above the value loss is due to two effects: On the one hand, potential rents that can be realized internally when trading with $S$ are forgone when $U_{1}$ buys on the market. But additionally, $U_{1}$ 's decision not to buy from $S$ will damage the supplier's reputation. Other potential clients will conclude that the product quality is low and the supplier will receive less external orders.

The boundaries for $\lambda$ derived in Proposition 5 can be given as functions of $R_{M}$. The manager will only always choose the low effort level if $R_{M}$ is larger than

$$
\max \left\{\frac{R_{M}-R_{1 L}}{\Pi_{1 L}+\Pi_{2}}, \min \left\{\frac{\left(R_{M}-R_{1 L}\right)\left(R_{M}-E\left[R_{2} \mid \tau_{L}\right]\right)}{\left(1-\tau_{L}\right)\left(R_{M}-R_{2 L}\right)\left(\frac{c}{w\left(\tau_{H}-\tau_{L}\right)}-\left(\Pi_{1 H}-\Pi_{1 L}\right)\right.}, \frac{R_{M}-R_{1 L}}{\Pi_{1 L}}\right\}\right\}
$$

and the high one if $R_{M}$ is smaller than

$$
\max \left\{\frac{R_{M}-R_{1 L}}{\Pi_{1 L}+\Pi_{2}}, \min \left\{\frac{\left(R_{M}-R_{1 L}\right)\left(R_{M}-E\left[R_{2} \mid \tau_{H}\right]\right)}{\left(1-\tau_{H}\right)\left(R_{M}-R_{2 L}\right)\left(\frac{c}{w\left(\tau_{H}-\tau_{L}\right)}-\left(\Pi_{1 H}-\Pi_{1 L}\right)\right.}, \frac{R_{M}-R_{1 L}}{\Pi_{1 L}}\right\}\right\} .
$$

From the proof of Proposition 5 the former boundary is weakly higher than the latter. Both are illustrated in Figure 4 for an example. As before, the revenue when buying on the market is drawn on the abscissa and the ownership share on the ordinate. For this figure it has been assumed that $R_{1 L}=R_{2 L}$ such that the boundaries are indeed piecewise linear. The boundaries are drawn as bold lines. For low or very high values 
of $R_{M}$ both boundaries coincide as they are either equal to $\lambda_{L}$ or $\lambda_{H}$.

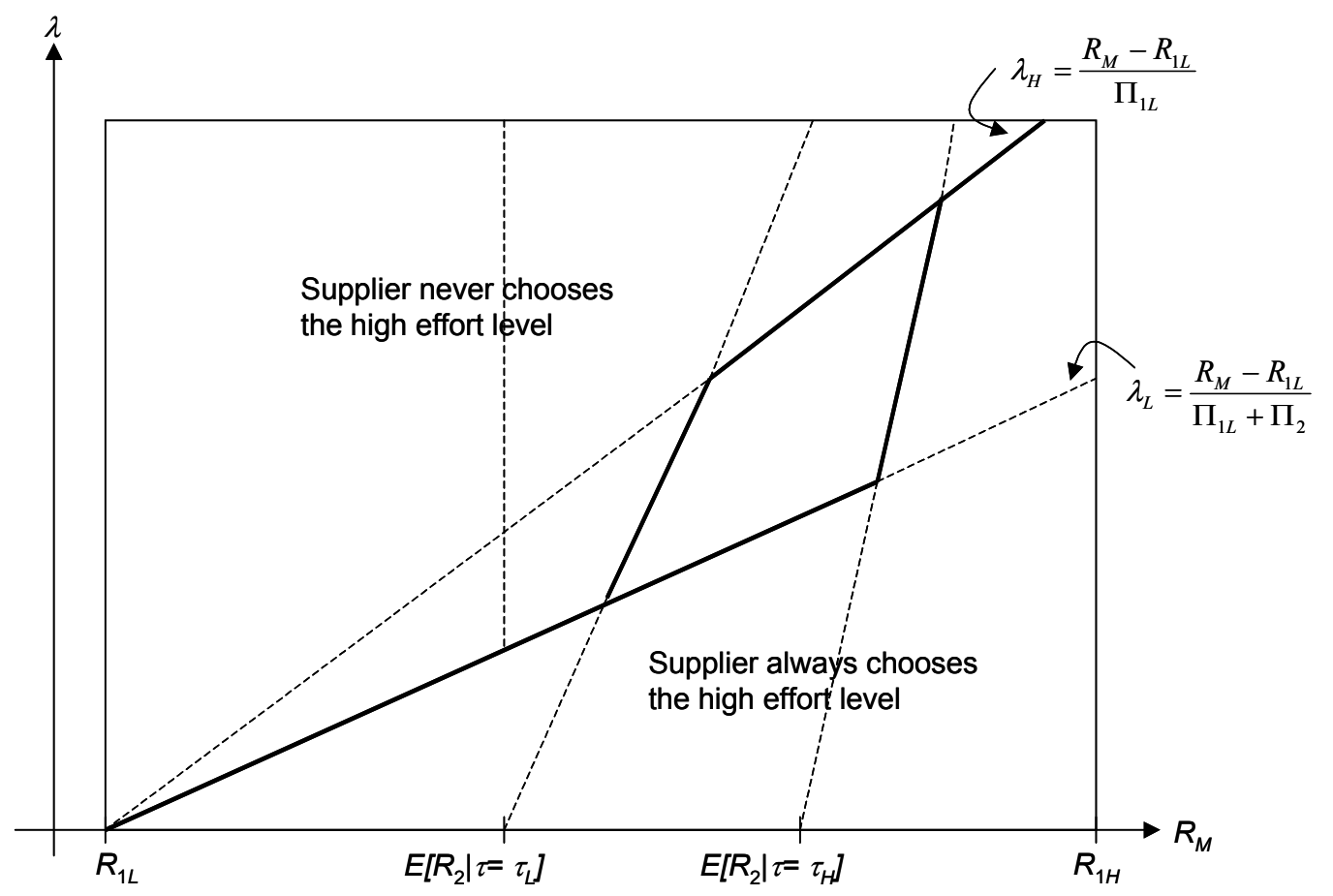

Figure 4: The Manager's effort choice

Note that the manager will always choose the high effort level if $\lambda<\lambda_{L}$. From Proposition 3 we know that in this case $U_{1}$ will never have an interest in buying the input at the low quality. Hence, the supplier will be able to sell the good if and only if the quality is high. In that case the good will be sold to both clients $U_{1}$ and $U_{2}$. By Assumption 2 this leads to high incentives. It is also possible that the high effort level is chosen when $\lambda$ is larger than $\lambda_{L}$ but smaller than $\lambda_{H}$. This is the case when a semiseparating equilibrium exists in the game between $U_{1}$ and $U_{2}$, in which $U_{1}$ buys from $S$ even at the low quality with a probability that is sufficiently small. As the proposition shows this may indeed be the case if $\lambda$ is not too large.

This will never happen if $\lambda>\lambda_{L}$ and $R_{M}<E\left[R_{2} \mid \tau_{L}\right]$. In that case we know from Proposition 1 that $U_{1}$ will buy from $S$, as its ownership share in $S$ is large and as it knows that $U_{2}$ will follow its decision as $U_{2}$ 's expected quality when buying from $S$ without further information is still higher than market quality. A high quality is only beneficial for the supplier as it may receive a higher profit in the internal trade with $U_{1}$. But by Assumption 3 this is not sufficient to create incentives for the manager to 
choose the high effort level.

If the ownership share $\lambda$ is even higher than $\lambda_{H}$ then $U_{1}$ will buy the good from $S$ at the low quality independent of $U_{2}$ 's procurement strategy. In that case its information on quality is also never revealed and - depending on the size of $R_{M}$ - the supplier always or never sells its product to $U_{2}$. Then of course incentives will neither suffice to induce the high effort level. It may also be the case that $M$ will never choose the high effort level if $R_{M}>E\left[R_{2} \mid \tau_{L}\right]$ and $\lambda$ is between $\lambda_{L}$ and $\lambda_{H}$, where we know from Proposition 4 that a semi-separating equilibrium exists. This may be the case if $\lambda$ is sufficiently large in this area. Note that in the quadrangle between the two bold lines only equilibria exist in which the manager plays a mixed strategy.

The effect shown here, that vertical integration weakens the supplier's incentives, is related to the idea of a 'soft budget constraint' in the literature on privatization of public companies: ${ }^{13}$ Managers of public companies anticipate that the government will help out when liquidity problems arise and therefore exert less effort to reduce costs.

\section{E When is a Spin-Off Beneficial?}

Until now, the ownership share $\lambda$ has been treated as exogenous and the impact of a given share on the procurement decision and management incentives has been analyzed. Now we want to investigate for a particular case, how this ownership share should optimally be chosen.

Of course many more factors matter for the decision on vertical integration in practice. In this model, we can only shed light on a small subarea of those factors. We therefore consider a very simple case to illustrate the two most important effects arising from the theory presented here. It is best understood by thinking of a situation where the parent company considers a spin-off of the supplier.

As laid out in the introduction, we look at a situation where the parent company will in any case keep its informational advantage over other clients. This may be due to the fact that it is still an important client of the supplier for other components, as for instance in the GM/Delphi example discussed in the introduction. Hence, $U_{1}$ will in any case learn the input quality before it makes its procurement decision. Hence, we examine a situation of a company having a close relationship with a supplier such that it has an informational advantage relative to other clients of the supplier independent of the ownership structure. Of course another possibility would be to impose for ex- 
ogenous reasons that the informational advantage depends on the size of the ownership share $\lambda$. There is a controversial discussion in the literature on the question whether vertical integration should by assumption come along with a change in the information structure. ${ }^{14}$ Here, we avoid this discussion and intentionally take the information structure as given and focus on the effects of the size of the ownership share on a company's decision to buy components from a supplier and the incentives of the supplier's management. This gives us a structure where the impact of $\lambda$ on the total outcome is purely endogenous.

We assume that the decision about $\lambda$ is made by maximizing the sum of expected firm values of supplier and parent company ex-ante before the manager chooses his effort level and the quality is realized. In unrestricted negotiations among all owners of the supplier the share of ownership for $U_{1}$ should indeed be chosen in this way as long as all have enough funds which we assume. We furthermore assume that the other client $U_{2}$ cannot take part in the negotiations. ${ }^{15}$ The sum of expected firm values of $U_{1}$ and $S$ is:

$$
E_{\tau}\left[x_{1} R_{1}(q)+\left(1-x_{1}\right) R_{M}+\left(x_{1} \Pi_{1}(q)+x_{2} \Pi_{2}\right)\right] .
$$

Note that this expression depends on $U_{1}$ 's ownership share $\lambda$ only via its effects on the equilibrium actions.

Recall that $U_{1}$ 's procurement decision creates an information externality as the supplier's reputation is affected by $U_{1}$ 's decision. Hence, the ownership share $\lambda$ has two effects on the value of both firms. On the one hand, it affects the ex-ante incentives of the supplier's management, but on the other hand it determines to what extent the information externality of $U_{1}$ 's decision on $S$ is internalized by $U_{1}$ ex-post. Whereas a low $\lambda$ seems to be beneficial if only the first effect is taken into account, the second effect makes higher values of $\lambda$ more attractive. To see the latter just note that for $\lambda=1$ the parent company's total profit after the quality has been realized as given in equation (1) is exactly equal to the total value of $U_{1}$ and $S$. Hence, when $\lambda=1$ the parent company's procurement decision will always be ex-post optimal. However, with high values of $\lambda$ there may be too weak incentives for the manager to improve quality.

To clarify both effects in a most simple case we assume that it will be ex-post optimal for total firm value that $U_{1}$ buys at the low quality if the information externality on $S$ is fully taken into account by $U_{1}$ : 
Assumption 4: If $U_{2}$ always follows $U_{1}$ 's procurement decision, then buying from $S$ is beneficial for $U_{1}$ when it completely owns $S$, i.e. $R_{1 L}+\Pi_{1 L}+\Pi_{2}>R_{M}$.

To simplify analysis further we only consider the case in which there are always equilibria in pure strategies in the signaling game. Hence we impose the following assumption:

Assumption 5: Without further information, $U_{2}$ will always buy from $S$, i.e. $E\left[R_{2} \mid \tau_{L}\right] \geq$ $R_{M}$.

If the ownership share $\lambda$ is below $\lambda_{L}$, then we know from Proposition 3 that there is always a separating equilibrium, in which the parent company $U_{1}$ buys only at the high quality and the other client $U_{2}$ always follows $U_{1}$ 's decision. If the ownership share is larger than $\lambda_{L}$, it follows from Proposition 1, that both companies buy from $S$ regardless of the quality offered. From Proposition 5, finally, we know that a small ownership share below $\lambda_{L}$ induces the high effort level and a large one above $\lambda_{L}$ the low effort level. Note that the total firm value is the same for any $\lambda$ below $\lambda_{L}$ as the equilibrium is unaltered by the exact value of $\lambda$ in this region. The same of course holds for all $\lambda$ above $\lambda_{L}$.

Hence, the sum of firm values for a high ownership share $\left(\lambda>\lambda_{L}\right)$ is

$$
\tau_{L}\left(R_{1 H}+\Pi_{1 H}+\Pi_{2}\right)+\left(1-\tau_{L}\right)\left(R_{1 L}+\Pi_{1 L}+\Pi_{2}\right)
$$

and for a low share $\left(\lambda<\lambda_{L}\right)$ it is given by

$$
\tau_{H}\left(R_{1 H}+\Pi_{1 H}+\Pi_{2}\right)+\left(1-\tau_{H}\right) R_{M}
$$

By comparing both expressions we can analyze, whether a high or a low degree of integration is optimal. We obtain the following result:

Proposition 6 If $E\left[R_{2} \mid \tau_{L}\right]>R_{M}$, then there is a cut-off value $\left.\bar{\tau}_{H} \in\right] \tau_{L}, 1\left[\right.$ for $\tau_{H}$, such that a spin-off with a low ownership share $\left(\lambda<\lambda_{L}\right)$ is beneficial if and only if $\tau>\bar{\tau}_{H}$ and otherwise a high ownership share $\left(\lambda \geq \lambda_{L}\right)$. 
As becomes clear from this result there is the following trade-off: ${ }^{16}$ On the one hand, reducing the ownership share increases the incentives of the supplier's management to exert the high effort. On the other hand, a high ownership share leads to an internalization of the external effect of $U_{1}$ 's decision on the supplier's reputation. If $\tau_{H}$ is sufficiently large for a given value of $\tau_{L}$, the management incentives are important. A high effort by the manager to raise the quality of the inputs has a large effect on realized quality. In that case the incentive aspect outweighs the internalization aspect and a lower ownership share is beneficial. If, in contrast, $\tau_{H}$ is not much larger than $\tau_{L}$, then incentives are less important, as effort only has a weak impact on the quality supplied by $S$. In that case a high ownership share is optimal.

\section{F Consequences}

\section{F.1 The Costs and Benefits of Vertical Integration}

Like any economic model our theory can only serve to highlight some aspects out of the manifold factors that are important, when the extent of vertical integration is considered in practice.

As one disadvantage of vertical integration it is often mentioned in practice that it reduces strategic flexibility. ${ }^{17}$ As viewed from the model this can be interpreted as follows: If the parent company owns a large share in the supplier, then the decision flexibility is reduced, as switching the supplier - here due to low quality - is less easy, as this brings about a lower value of the ownership share. Note that the upstream business of the parent company may suffer from this effect, although it may be beneficial for the structure as a whole as it has to cope with the lower quality input.

Picot (1991) points out, that from the typical enumerations of costs and benefits of vertical integration from a practical viewpoint, it remains unclear whether in-house production or external procurement leads to products of higher quality. Our model makes a clear prediction for this question: The expected quality should be higher when the supplier is independent, as an independent supplier has higher incentives to raise the quality levels.

In Picot's article practical policy oriented arguments are contrasted with transaction cost considerations. As a consequence of these considerations he recommends, that outsourcing should be optimal, for "simple, that is well structured, standardized 
and certain, i.e. well plannable corporate activities". Activities should however be kept in-house, "if they are strategically important and innovative, specific and uncertain and occur frequently". ${ }^{18}$ Our model partially points in the opposite direction. If some activity is barely standardized, then it will be more likely that quality will be uncertain and realized quality will depend strongly on the supplier's effort. But, as we have seen, an integrated supplier may be tempted to rely on selling internally even when the quality provided does not attain the quality offered by external suppliers. Hence, its management and employees may have weaker incentives to attain quality improvements. Recent organizational patterns in the automotive industry point in that direction, as even very complex activities are carried on by independent suppliers and external service providers.

Not only in transaction cost theory but also in the literature on incomplete contracts the specifity of an activity is stressed as an important factor in determining vertical integration (compare the empirical studies by Monteverde and Teece (1982) or Masten (1984) or the theoretical analysis by Schmitz and Sliwka (2001)). In this respect, the model presented does not yield unambiguous conclusions. On the one hand, it might be argued that other potential clients may learn less from the decision of a parent company whether to buy from its own supplier when the input is very specific to the parent's needs. This would indicate that the signaling effect should be weak when inputs are specific. On the other hand, the decision not to buy a very specific input from the inhouse supplier anymore might be a very bad signal on this supplier's capabilities. In this respect the mentioned effects may even be stronger when specific activities are considered.

\section{F.2 Profit Centers in a Vertically Integrated Organization}

A different important question is what can be learned from the analysis for a company that is vertically integrated for the mentioned or other reasons. In many instances the separate production units will be governed as profit centers. In practice, there are very different concepts describing how profit centers should be administered and, most importantly, how much independence should be granted to each profit center (compare for instance Frese (1995)).

With the help of the analytical results of our model the optimal degree of independence for a profit center can be discussed in connection with the idea of selective intervention. One may think in the sense of the Williamsonian Gedankenexperiment 
of a holding company which owns the client as well as the supplier. Both are organized as independent profit centers. If the client's management is only interested in its own profits, then a threat of switching the supplier will indeed be credible. But this may not be in the interest of the company as a whole. Ex-post, after it becomes for instance clear that the supplier can provide only a low quality, it may be beneficial for the holding company to intervene and enforce the trade with the internal supplier. But if this is anticipated, incentives are reduced. It is therefore exactly this possibility of selective intervention, which reduces incentives.

A similar effect arises if subsidiaries are forced by rule enacted by the holding company to buy certain products only from an inhouse supplier, as is sometimes observed in practice. Again the inhouse supplier can rely on demand for its products by clients from the same group of companies and will have weaker incentives.

Hence, the analysis yields a recommendation for the internal organization of a vertically integrated company: Only a decentralized structure, in which the head quarter can commit credibly not to intervene in procurement decisions and to guarantee its own profit centers autonomy where to buy their inputs will be able to maintain high incentives.

Indeed this is one typical property that characterizes successful, vertically integrated groups of companies. Bertelsmann, one the world's largest publishing houses, for instance is also the owner of Mohndruck, one of the world's largest offset-printing companies. Nevertheless, at tenders of inhouse publishers Mohndruck is treated like any other external printing company. Mohndruck itself today earns only about $12 \%$ of total revenues with other Bertelsmann companies. Bertelsmann views exactly this compulsion for each profit center to survive on the market as a decisive part of its own culture of a decentralized profit center organization. ${ }^{19}$

Nonetheless, the model presented indicates that the autonomy of profit centers is in danger even in strongly decentralized organizations when procurement decisions are extremely important for inhouse suppliers. In the short run intervention can indeed be optimal for the company as a whole. ${ }^{20}$ But as has been shown, it is the anticipation of possible interventions in favor of one part of the company that may reduce the incentives in an other part. 


\section{G Appendix}

\section{Proof of Lemma 1:}

(i) Suppose that there is an equilibrium $\left(\alpha_{L}, \alpha_{H}, \beta_{0}, \beta_{1}, \hat{\tau}_{0}, \hat{\tau}_{1}\right)$ in which $U_{1}$ does not always buy from $S$ if quality is high (i.e. $\alpha_{H}<1$ ). For this to be the case, we must have in such an equilibrium that:

$$
R_{M}+\lambda \beta_{0} \Pi_{2} \geq R_{1 H}+\lambda\left(\Pi_{1 H}+\beta_{1} \Pi_{2}\right)
$$

But from (10) it directly follows that

$$
R_{M}+\lambda \beta_{0} \Pi_{2}>R_{1 L}+\lambda\left(\Pi_{1 L}+\beta_{1} \Pi_{2}\right)
$$

and therefore we must have that $\alpha_{L}=0$. If in that case $\alpha_{H}>0$ then $U_{2}$ can conclude from $x_{1}=1$ that $q=q_{H}$ and it will always buy from $S\left(\beta_{1}=1\right)$ and (10) can never hold. Hence, if an equilibrium exists, in which $U_{1}$ does not always buy the good at the high quality, then this must be a pooling equilibrium with $\alpha_{H}=\alpha_{L}=0$ and beliefs $\hat{\tau}_{0}=\tau$.

If $E\left[R_{2} \mid \hat{\tau}_{0}\right]=E\left[R_{2} \mid \tau\right]<R_{M}$ then $U_{2}$ would never buy from $S$ when $U_{1}$ has not done that $\left(\beta_{0}=0\right)$ but in turn $U_{1}$ would be better off with $x_{1}=1$ and this leads to a contradiction. We therefore must have that $E\left[R_{2} \mid \tau\right] \geq R_{M}$.

But we can conclude from (10) again that $\beta_{1}<\beta_{0}$ and therefore $\beta_{1}<1$ which is only possible if $E\left[R_{2} \mid \hat{\tau}_{1}\right] \leq R_{M}$. But then $\hat{\tau}_{0} \geq \hat{\tau}_{1}$ which contradicts the monotonicity of beliefs.

(ii) We know from part (i) that $\alpha_{H}=1$. If $\alpha_{L}<1$, then the other client $U_{2}$ directly learns from $x_{1}=0$ that $q=q_{L}$. Hence, $U_{2}$ will never buy from $S$, when $U_{1}$ hasn't and $\beta_{0}=0$. If, however, $\alpha_{L}=1$ then $U_{1}$ will always buy from $S$ on the equilibrium path.

\section{Proof of Propositions 1 to 4:}

Recall that any equilibrium is described by a vector $\left(\alpha_{L}, \alpha_{H}, \beta_{0}, \beta_{1}, \hat{\tau}_{0}, \hat{\tau}_{1}\right)$. By the results of Lemma 1 we can restrict the analysis to equilibria with $\alpha_{H}=1, \beta_{0}=0$. To investigate existence conditions for all possible equilibria we characterize all possible equilibria and derive necessary and sufficient conditions for the existence in each case. Note that $\hat{\tau}_{0}$ is either 0 if $\alpha_{L}<1$ or it can be freely specified as it is off the equilibrium 
path. From equation (2), which describes $U_{2}$ 's beliefs after observing $x_{1}=1$, we can compute $\hat{\tau}_{1}$ and each equilibrium is fully characterized by a vector $\left(\alpha_{L}, \beta_{1}\right)$. The equilibria are illustrated in Figure 3.

(a) $\alpha_{L}=1, \beta_{1}=1$ : Pooling equilibrium, both always buy from $S$

For $\alpha_{L}=1$ it must be optimal for $U_{1}$ to buy a low quality if $U_{2}$ follows the decision, i.e. $R_{1 L}+\lambda\left(\Pi_{1 L}+\Pi_{2}\right) \geq R_{M}$, which is equivalent to

$$
\lambda \geq \frac{R_{M}-R_{1 L}}{\Pi_{1 L}+\Pi_{2}} \equiv \lambda_{L}
$$

For $\beta_{1}=1$ to be optimal, $R_{M} \leq E\left[R_{2} \mid \tau\right]$ must hold. Both conditions are therefore necessary and sufficient for the existence of such an equilibrium.

(b) $\alpha_{L}=1, \beta_{1}=0$ : Pooling equilibrium, $U_{1}$ always buys from $S, U_{2}$ never follows If $\alpha_{L}=1$ in that case, then $R_{1 L}+\lambda \Pi_{1 L} \geq R_{M}$ must hold. This is equivalent to

$$
\lambda \geq \frac{R_{M}-R_{1 L}}{\Pi_{1 L}} \equiv \lambda_{H}
$$

For $\beta_{1}=0$, it must be the case that $R_{M} \geq E\left[R_{2} \mid \tau\right]$.

(c) $\alpha_{L}=0, \beta_{1}=1$ : Separating equilibrium, $U_{1}$ buys from $S$ only at high quality, $U_{2}$ follows

For $\alpha_{L}=0$ we must have that $R_{1 L}+\lambda\left(\Pi_{1 L}+\Pi_{2}\right) \leq R_{M}$, or

$$
\lambda \leq \frac{R_{M}-R_{1 L}}{\Pi_{1 L}+\Pi_{2}}=\lambda_{L}
$$

$\beta_{1}=1$ is always optimal in this case, as $R_{M}<R_{2 H}$.

(d) $\alpha_{L}=0, \beta_{1}=0$ : Separating equilibrium, $U_{1}$ buys only at high quality, $U_{2}$ never buys

This can never arise as for $\alpha_{L}=0$ it will always be the case that $\beta_{1}=1$.

(e) $0<\alpha_{L}<1,0<\beta_{1}<1$ : Semi-separating equilibrium, both randomize

If $U_{1}$ randomizes when $q=q_{L}$, it must be indifferent between buying from $S$ and 
buying on the market, and $R_{1 L}+\lambda\left(\Pi_{1 L}+\beta_{1} \Pi_{2}\right)=R_{M}$ must hold. Hence,

$$
\beta_{1}=\frac{R_{M}-R_{1 L}}{\lambda \Pi_{2}}-\frac{\Pi_{1 L}}{\Pi_{2}} .
$$

If $U_{2}$ randomizes, it must also be indifferent between buying from $S$ and on the market after observing $x_{1}=1$ :

$$
\begin{aligned}
& E\left[R_{2} \mid x_{1}=1 ; \tau\right]=R_{M} \Leftrightarrow \\
& \frac{\tau}{\tau+(1-\tau) \alpha_{L}} R_{2 H}+\left(1-\frac{\tau}{\tau+(1-\tau) \alpha_{L}}\right) R_{2 L}=R_{M} \Leftrightarrow \\
& \frac{\tau R_{2 H}+(1-\tau) \alpha_{L} R_{2 L}}{\tau+(1-\tau) \alpha_{L}}=R_{M} .
\end{aligned}
$$

Hence,

$$
\alpha_{L}=\frac{\tau\left(R_{2 H}-R_{M}\right)}{(1-\tau)\left(R_{M}-R_{2 L}\right)} .
$$

It is easy to check that these values of $\alpha_{L}$ and $\beta_{1}$ are strictly between 0 and 1 , iff

$$
\begin{aligned}
& \frac{R_{M}-R_{1 L}}{\Pi_{1 L}}>\lambda>\frac{R_{M}-R_{1 L}}{\Pi_{2}+\Pi_{1 L}} \text { and } \\
& E\left[R_{2} \mid \tau\right]<R_{M} .
\end{aligned}
$$

(f) $\alpha_{L}=1,0<\beta_{1}<1$ : Pooling equilibrium, $U_{1}$ always buys from $S$, $U_{2}$ randomizes when $U_{1}$ has bought

If $U_{2}$ plays a mixed strategy $\left(0<\beta_{1}<1\right)$ we must have

$$
E\left[R_{2} \mid \tau\right]=R_{M}
$$

For $\alpha_{L}=1$ it must be optimal for $U_{1}$ to buy a low quality if $U_{2}$ follows the decision with probability $\beta_{1}$, i.e. $R_{1 L}+\lambda\left(\Pi_{1 L}+\beta_{1} \Pi_{2}\right) \geq R_{M}$, which is equivalent to

$$
\beta_{1} \geq \frac{R_{M}-R_{1 L}}{\lambda \Pi_{2}}-\frac{\Pi_{1 L}}{\Pi_{2} \lambda} .
$$

Such a $\beta_{1}$ can be found iff the right-hand side is smaller than one or

$$
\lambda>\frac{R_{M}-R_{1 L}}{\Pi_{1 L}+\Pi_{2}}=\lambda_{L} .
$$


(g) $0<\alpha_{L}<1$, $\beta_{1}=1$ : Semi-separating equilibrium, $U_{2}$ always follows $U_{1}$ If $U_{1}$ randomizes we must have that

$$
\lambda=\frac{R_{M}-R_{1 L}}{\Pi_{1 L}+\Pi_{2}}=\lambda_{L}
$$

$U_{2}$ will follow $U_{1}$ (using (2)) if

$$
\begin{aligned}
& \frac{\tau}{\tau+(1-\tau) \alpha_{L}} R_{2 H}+\left(1-\frac{\tau}{\tau+(1-\tau) \alpha_{L}}\right) R_{2 L} \geq R_{M} \Leftrightarrow \\
& \frac{\tau\left(R_{2 H}-R_{M}\right)}{(1-\tau)\left(R_{M}-R_{2 L}\right)} \geq \alpha_{L} .
\end{aligned}
$$

Such an $\alpha_{L}$ always exists as the left-hand side is always larger than zero.

(h) $0<\alpha_{L}<1, \beta_{1}=0$ : Semi-separating equilibrium, $U_{2}$ never follows $U_{1}$ Again

$$
\lambda=\frac{R_{M}-R_{1 L}}{\Pi_{1 L}}=\lambda_{H}
$$

and

$$
\begin{aligned}
& \frac{\tau}{\tau+(1-\tau) \alpha_{L}} R_{2 H}+\left(1-\frac{\tau}{\tau+(1-\tau) \alpha_{L}}\right) R_{2 L} \leq R_{M} \Leftrightarrow \\
& \frac{\tau\left(R_{2 H}-R_{M}\right)}{(1-\tau)\left(R_{M}-R_{2 L}\right)} \leq \alpha_{L} .
\end{aligned}
$$

Such an $\alpha_{L}$ exists if the left-hand side is smaller than one, or

$$
\tau\left(R_{2 H}-R_{M}\right)<(1-\tau)\left(R_{M}-R_{2 L}\right) \Leftrightarrow R_{M}>E\left[R_{2} \mid \tau\right]
$$

The case where $\alpha_{L}=0$ and $0<\beta_{1}<1$ is ruled out by claim (ii) of Lemma 1 . As all feasible strategy combinations have been considered, we can conclude from the sufficient conditions for cases (f)-(h) that in cases (a) to (c) and (e) the equilibria are unique for the generic cases where inequalities are strict in the given conditions.

\section{Proof of Proposition 5:}


(i) Given equilibrium (mixed) strategies $\alpha_{L}$ and $\beta_{1}$ we know from equation (8) that a necessary condition for $\tau=\tau_{L}$ to be chosen in equilibrium is that

$$
\Pi_{1 H}+\beta_{1} \Pi_{2}-\alpha_{L}\left(\Pi_{1 L}+\beta_{1} \Pi_{2}\right) \leq \frac{c}{\left(\tau_{H}-\tau_{L}\right) \mu} .
$$

Suppose that the manager chooses $\tau_{L}$. From Proposition 1 we know that in this case $\alpha_{L}=1$ if $\lambda>\lambda_{L}$ and $R_{M}<E\left[R_{2} \mid \tau_{L}\right]$. By Proposition 2 the same holds if $\lambda>\lambda_{H}$ (see also Figure 3). In both cases condition (12) will always hold by Assumption 3 and the manager will indeed optimally choose $\tau_{L}$. Hence, for $R_{M}<E\left[R_{2} \mid \tau_{L}\right]$ with $\lambda>\lambda_{L}$ or if $\lambda>\lambda_{H}$ there will always be an equilibrium with $\tau=\tau_{L}$.

However, if $\lambda<\lambda_{L}$ we will always have that $\alpha_{L}=0$ and $\beta_{1}=1$ by Proposition 3 . In that case (12) can never hold by Assumption 2 and we can never have an equilibrium with $\tau=\tau_{L}$. Hence, only the case where $R_{M}>E\left[R_{2} \mid \tau_{L}\right]$ and $\lambda_{L}<\lambda<\lambda_{H}$ remains to be examined. From Proposition 4 we know that there will be a semi-separating equilibrium. From case (e) in the proof of Propositions 1-4 for $\tau=\tau_{L}$ it follows, that

$$
\begin{aligned}
\beta_{1} & =\frac{1}{\Pi_{2}}\left(\frac{R_{M}-R_{1 L}}{\lambda}-\Pi_{1 L}\right) \text { and } \\
\alpha_{L} & =\frac{\tau_{L}\left(R_{2 H}-R_{M}\right)}{\left(1-\tau_{L}\right)\left(R_{M}-R_{2 L}\right)} .
\end{aligned}
$$

We can now insert theses values of $\beta_{1}$ and $\alpha_{L}$ in equation (12)

$$
\begin{gathered}
\Pi_{1 H}+\left(\frac{R_{M}-R_{1 L}}{\lambda}-\Pi_{1 L}\right)-\frac{\tau_{L}\left(R_{2 H}-R_{M}\right)}{\left(1-\tau_{L}\right)\left(R_{M}-R_{2 L}\right)} \frac{R_{M}-R_{1 L}}{\lambda} \leq \frac{c}{\left(\tau_{H}-\tau_{L}\right) \mu} \\
\Leftrightarrow 1-\frac{\tau_{L}\left(R_{2 H}-R_{M}\right)}{\left(1-\tau_{L}\right)\left(R_{M}-R_{2 L}\right)} \leq \lambda \frac{\frac{c}{\left(\tau_{H}-\tau_{L}\right) \mu}-\left(\Pi_{1 H}-\Pi_{1 L}\right)}{R_{M}-R_{1 L}} \Leftrightarrow \\
\frac{\left(1-\tau_{L}\right)\left(R_{M}-R_{2 L}\right)-\tau_{L}\left(R_{2 H}-R_{M}\right)}{\left(1-\tau_{L}\right)\left(R_{M}-R_{2 L}\right)} \leq \lambda \frac{\frac{c}{\left(\tau_{H}-\tau_{L}\right) \mu}-\left(\Pi_{1 H}-\Pi_{1 L}\right)}{R_{M}-R_{1 L}} .
\end{gathered}
$$

As $\frac{c}{\left(\tau_{H}-\tau_{L}\right) \mu}-\left(\Pi_{1 H}-\Pi_{1 L}\right)$ is positive by Assumption 3, this is equivalent to

$$
\lambda \geq \frac{\left(R_{M}-R_{1 L}\right)\left(R_{M}-E\left[R_{2} \mid \tau_{L}\right]\right)}{\left(1-\tau_{L}\right)\left(R_{M}-R_{2 L}\right)\left(\frac{c}{\left(\tau_{H}-\tau_{L}\right) \mu}-\left(\Pi_{1 H}-\Pi_{1 L}\right)\right)} .
$$

This yields a boundary condition in the region where $R_{M}$ is larger than $E\left[R_{2} \mid \tau_{L}\right]$ and $\lambda$ lies between $\lambda_{L}$ and $\lambda_{H}$. Note that this boundary is negative for $R_{M}<E\left[R_{2} \mid \tau_{L}\right]$. 
(ii) Note that we cannot conclude that the manager always chooses a high effort if the conditions derived in part (i) are not satisfied as there may be equilibria with mixed strategies played by the manager as well. But we can proceed analogously to (i) by checking necessary conditions for a pure strategy equilibrium where $\tau=\tau_{H}$. We must now have that

$$
\Pi_{1 H}+\beta_{1} \Pi_{2}-\alpha_{L}\left(\Pi_{1 L}+\beta_{1} \Pi_{2}\right) \geq \frac{c}{\left(\tau_{H}-\tau_{L}\right) \mu} .
$$

Suppose that $\tau_{H}$ is always chosen. If $\lambda>\lambda_{H}$ we know from Proposition 2 that $\alpha_{L}=1$. The same holds if $\lambda>\lambda_{L}$ and $R_{M}<E\left[R_{2} \mid \tau_{H}\right]$ by Proposition 1. But in that case condition (14) will never hold by Assumption 3. Hence, for $R_{M}<E\left[R_{2} \mid \tau_{H}\right]$ and $\lambda>\lambda_{L}$ or if $\lambda>\lambda_{H}$ we will never have a pure strategy equilibrium with $\tau=\tau_{H}$.

However, if $\lambda<\lambda_{L}$ we will always have that $\alpha_{L}=0$ and $\beta_{1}=1$ by Proposition 3. Hence, condition (14) always hold by Assumption 2 and we will always have an equilibrium with $\tau=\tau_{H}$. Finally, we have to check the region where $\lambda_{L}<\lambda<$ $\lambda_{H}$ and $R_{M}>E\left[R_{2} \mid \tau_{H}\right]$. We know from Proposition 4 that there will be a semiseparating equilibrium in the game played between $U_{1}$ and $U_{2}$ for given $\tau=\tau_{H}$. As before we know the equilibrium values of $\alpha_{L}$ and $\beta_{1}$ from case (e) in Proposition 4. Note, that of course we now have to use $\tau_{H}$ instead of $\tau_{L}$ in the expression for $\alpha_{L}$. Proceeding as before we obtain

$$
\lambda \leq \frac{\left(R_{M}-R_{1 L}\right)\left(R_{M}-E\left[R_{2} \mid \tau_{H}\right]\right)}{\left(1-\tau_{H}\right)\left(R_{M}-R_{2 L}\right)\left(\frac{c}{\left(\tau_{H}-\tau_{L}\right) \mu}-\left(\Pi_{1 H}-\Pi_{1 L}\right)\right)}
$$

The right-hand side of this expression corresponds to that of (13) where $\tau_{L}$ is replaced by $\tau_{H}$. It is lower than (13) as

$$
\begin{aligned}
& \frac{\left(R_{M}-E\left[R_{2} \mid \tau_{L}\right]\right)}{\left(1-\tau_{L}\right)}>\frac{\left(R_{M}-E\left[R_{2} \mid \tau_{H}\right]\right)}{\left(1-\tau_{H}\right)} \\
\Leftrightarrow & E\left[R_{2} \mid \tau_{H}\right]\left(1-\tau_{L}\right)-E\left[R_{2} \mid \tau_{L}\right]\left(1-\tau_{H}\right)>R_{M}\left(\tau_{H}-\tau_{L}\right) \\
\Leftrightarrow & \left(\tau_{H} R_{2 H}+\left(1-\tau_{H}\right) R_{2 L}\right)\left(1-\tau_{L}\right) \\
& -\left(\tau_{L} R_{2 H}+\left(1-\tau_{L}\right) R_{2 L}\right)\left(1-\tau_{H}\right)>R_{M}\left(\tau_{H}-\tau_{L}\right) \\
\Leftrightarrow & R_{2 H}>R_{M} .
\end{aligned}
$$

which always the case. 


\section{Proof of Proposition 6:}

The sum of firm values is larger with a low ownership share $\lambda<\lambda_{L}$, when

$$
\begin{aligned}
& \tau_{H}\left(R_{1 H}+\Pi_{1 H}+\Pi_{2}\right)+\left(1-\tau_{H}\right) R_{M} \\
& >\tau_{L}\left(R_{1 H}+\Pi_{1 H}+\Pi_{2}\right)+\left(1-\tau_{L}\right)\left(R_{1 L}+\Pi_{1 L}+\Pi_{2}\right) .
\end{aligned}
$$

Note already that this is always true for $\tau_{H}=1$. If, however, $\tau_{H}=\tau_{L}$, then the inequality is never met because of Assumption 4, as it is equivalent to $R_{M}>R_{1 L}+$ $\Pi_{1 L}+\Pi_{2}$ in that case. By solving for $\tau_{H}$, we get the cut-off value

$$
\tau_{H}>\tau_{L} \frac{R_{1 H}+\Pi_{1 H}-R_{1 L}-\Pi_{1 L}}{R_{1 H}+\Pi_{1 H}+\Pi_{2}-R_{M}}+\frac{R_{1 L}+\Pi_{1 L}+\Pi_{2}-R_{M}}{R_{1 H}+\Pi_{1 H}+\Pi_{2}-R_{M}} .
$$

\section{References}

Bénabou, R. and Tirole, J. (2002): Intrinsic and Extrinsic Motivation. Mimeo IDEI Toulouse.

Bundeskartellamt (2002): Bundeskartellamt. 8. Beschlussabteilung. B 8 40000-U$109 / 01$.

Carlton, D. W. (1979): Vertical Integration in Competitive Markets under Uncertainty. Journal of Industrial Economics, 27, pp. 189-209.

Chiu, Y. S. (1998): Noncooperative Bargaining, Hostages, and Optimal Asset Ownership. American Economic Review, 88, pp. 882-901.

Coase, R. (1937): The Nature of the Firm. Economica, 4, pp. 386-405.

De Meza, D. and Lockwood, B. (1998): Does Asset Ownership Always Motivate Managers? The Property Rights Theory of the Firm with Alternating-Offers Bargaining. Quarterly Journal of Economics, 113, pp. 361-386. 
Fandel, G. and Lorth, M. (1999): Portefeuilletheoretische Überlegungen zur Entscheidung über Eigenfertigung oder Fremdbezug. Zeitschrift für Betriebswirtschaft, 69, pp. 1423-1444.

Fehr, E., Klein, A. and Schmidt, K. M. (2002): Fairness, Incentives, and Contractual Incompleteness. Mimeo, University of Munich.

Frese, E. (1995): Profit Center und Verrechnungspreis. Zeitschrift für betriebswirtschaftliche Forschung, 47, pp. 942-954.

Grossman, S. J. and Hart, O. D. (1986): The Costs and Benefits of Ownership: A Theory of Vertical and Lateral Integration. Journal of Political Economy, 94, pp. 691-719.

Hart, O. D. and Moore, J. (1990): Property Rights and the Nature of the Firm. Journal of Political Economy, 98, pp. 1119-1158.

Masten, S. (1984): The Organization of Production: Evidence from the Aerospace Industry. Journal of Law and Economics, 27, pp. 403-418.

Mohn, R. (1986): Erfolg durch Partnerschaft. Siedler Verlag, Berlin, 3. edition.

Monteverde, K. and Teece, D. (1982): Supplier Switching Costs and Vertical Integration in the Automobile Industry. Bell Journal of Economics, 13, pp. 206-213.

Picot, A. (1991): Ein neuer Ansatz zur Gestaltung der Leistungstiefe. Zeitschrift für betriebswirtschaftliche Forschung, 43, pp. 336-357.

Riordan, M. H. (1990): What is Vertical Integration. In: Aoki, M., Gustafsson, B. and Williamson, O. E. (Ed.) The Firm as a Nexus of Treaties, Sage, New York, pp. 94-111.

Schmidt, K. M. (1996): The Costs and Benefits of Privatization: An Incomplete Contracts Approach. Journal of Law, Economics and Organization, 12, pp. 1-24.

Schmitz, P. and Rosenkranz, S. (2001): Vertikale Unternehmenskooperationen. In: Jost, P.-J. (Ed.) Die Prinzipal-Agenten-Theorie in der Betriebswirtschaftslehre, Schäffer-Poeschel, Stuttgart. 
Schmitz, P. W. and Sliwka, D. (2001): On Synergies and Vertical Integration. International Journal of Industrial Organisation, 19, pp. 1281-1295.

Tirole, J. (1988): The Theory of Industrial Organization. MIT Press, Cambridge, MA.

Whinston, M. D. (2000): On the Transaction Cost Determinants of Vertical Integration. Mimeo, Northwestern University.

Williamson, O. E. (1985): The Economic Institutions of Capitalism. The Free Press, New York. 


\section{Anmerkungen}

${ }^{1}$ Compare for instance "General Motors will den Autozulieferer Delphi abtrennen" in Frankfurter Allgemeine Zeitung, August, 51998.

${ }^{2}$ Even of Delphi's 29,1 billion Dollar annual revenue in the year 2000, 20,7 billion Dollar have been earned from transactons with GM. (Compare "Delphi results beat final-quarter expectation" in Financial Times January, 17 2001).

${ }^{3}$ Compare "GM to spin off remaining 80\% of Delphi" in Financial Times April, 13 1999.

${ }^{4}$ Compare Grossman and Hart (1986) and Hart and Moore (1990). For a recent comparison of the premises and consequences of Williamsonian transaction cost considerations and the theory of incomplete contracts and a discussion of both approaches in the light of empirical results compare Whinston (2000).

${ }^{5}$ De Meza and Lockwood (1998) and Chiu (1998) show, that this result depends on the exact nature of the bargaining process modelled. If strategic bargaining with outside options is modelled in a non-cooperative fashion instead of cooperative Nash bargaining, then it can indeed be optimal that even a non-investing party holds property rights.

${ }^{6}$ Hence, uncertain demand as analyzed in the models by Carlton (1979) or Fandel and Lorth (1999) as a possible explanation for vertical integration or the decision among inhouse procurement or outsourcing is of no importance in our model.

${ }^{7}$ Alternatively, one can assume without affecting the results that $U_{1}$ only observes a noisy signal on the prospective quality which is itself uncertain and can take two values. All payoffs can then simply be interpreted as conditional expectations of the true quality given this signal.

${ }^{8}$ Both assumptions help to simplify the equilibrium analysis significantly. The assumption that $R_{1 M}=R_{2 M}=R_{M}$ may for instance be justified on the grounds that $U_{1}$ and $U_{2}$ are of similar size and therefore need similar quantities of the input good. The assumption that $\Pi_{2}$ is constant is certainly a restriction as this does not allow that the price can vary with $U_{2}$ 's beliefs on the offered quality. It may be justified by refering to 
the practice of charging a pretermined fixed price when trading with external clients. A reason for this may be that the firm follow a 'no rebate' policy for reputational reasons which is of course outside the scope of the model.

${ }^{9}$ For other recent papers applying a similar refinement compare for instance Bénabou and Tirole (2002), p. 15 or Fehr et al. (2002), p. 36.

${ }^{10}$ Alternatively, such equilibria can be ruled out without imposing the condition on beliefs by simply assuming that $\Pi_{1 H}>\Pi_{2}$. To see this just note that for $\alpha_{H}<1$ we need $R_{M}+\lambda \beta_{0} \Pi_{2} \geq R_{1 H}+\lambda\left(\Pi_{1 H}+\beta_{1} \Pi_{2}\right)$. When $\Pi_{1 H}>\Pi_{2}$ this can never be the case regardless of $\beta_{0}$ and $\beta_{1}$.

${ }^{11}$ Indeed it is a typical argument heard in practice in favor of in-house supply that contribution margins are 'kept within the company'.

${ }^{12}$ Note that the manager has no prior private information.

${ }^{13}$ Compare for instance Schmidt (1996).

${ }^{14}$ Compare Riordan (1990) for an overview of the arguments.

${ }^{15}$ The objective of this analysis is to investigate a situation in which there is always another client of the supplier, who owns no capital share in $S$. This seems to be an appropriate assumption merely by reasons of competition policy. For instance the German Bundeskartellamt (Federal Cartel Office) explains the decision to stop EON's take-over of Gelsenberg on January 17, 2002 by claiming that common vertical ownership raises the probability of anticompetitive behavior (compare Bundeskartellamt (2002), § 55).

${ }^{16}$ Note that we resticted the analysis to the case where $E\left[R_{2} \mid \tau_{L}\right]>R_{M}$ to consider only pure strategy equilibria.

${ }^{17}$ Compare for instance Picot (1991), p. 343.

${ }^{18}$ Compare Picot (1991), p. 352 (translated by the author).

${ }^{19}$ These statements have been directly given by Edwin Eichler, CEO of Mohn Media. Reinhard Mohn, Bertelsmann's main owner, writes for instance on Bertelsmann's leadership concepts: "Self dependently operating managers optimize in first respect 
the success of their own profit centers. The interest of the company as a whole gets a lower attention.” (compare Mohn (1986), p. 85, translation by the author).

${ }^{20}$ As an example Thomas Middelhoff questioned shortly after taking over as CEO of Bertelsmann AG, whether it is indeed sensible for the company as a whole that the magazine "Stern", which by majority belongs to Bertelsmann, decided to add a free $\mathrm{CD}$ offered by competitor T-Online to a special issue on the internet and not one by the internet provider AOL Europe which at the time was partially owned by Bertelsmann (compare „Publisher with his eye on cyberspace” in Financial Times, December, 7 1998). 


\section{Zusammenfassung:}

In einem spieltheoretischen Signalisierungsmodell wurde gezeigt, dass ein vertikal mit einem eigenen Zulieferer integriertes Unternehmen möglicherweise auch dann Vorprodukte bei diesem Zulieferer bezieht, wenn diese von geringerer Qualität sind als von externen Zulieferern angebotene. Entscheidet sich das Unternehmen gegen den Kauf beim eigenen Zulieferer, so leidet dessen Qualitätsreputation und somit der Wert der Beteiligung. Es wurde gezeigt, dass dieser Effekt zu einer Schwächung der Anreize des Zulieferermanagements führt. Eine Reduktion der Beteiligung beispielsweise durch einen Spin-off des Zulieferers erleichtert die Generierung von Anreizen zur Qualitätsverbesserung.

\section{English Summary:}

In a game-theoretic signaling model it has been shown that a company which is vertically integrated with its own supplier will buy products from this supplier even when the quality of those products is lower than that offered by external competitors. If the company decides to purchase the product externally, the supplier's reputation and, hence, the value of the ownership share in the supplier is reduced. It has been shown that this effect leads to reduced incentives on the side of the management of the supplier. Furthermore, a reduction of the ownership share for instance by a spin-off of the supplier improves incentives for quality enhancements. 


\section{IZA Discussion Papers}

\begin{tabular}{|c|c|c|c|c|}
\hline No. & Author(s) & Title & Area & Date \\
\hline 842 & $\begin{array}{l}\text { M. Svarer } \\
\text { M. Rosholm } \\
\text { J. R. Munch }\end{array}$ & Rent Control and Unemployment Duration & 3 & $08 / 03$ \\
\hline 843 & $\begin{array}{l}\text { J. J. Heckman } \\
\text { R. Matzkin } \\
\text { L. Nesheim }\end{array}$ & Simulation and Estimation of Hedonic Models & 6 & $08 / 03$ \\
\hline 844 & D. Sliwka & On the Hidden Costs of Incentive Schemes & 1 & $08 / 03$ \\
\hline 845 & $\begin{array}{l}\text { G. Dewit } \\
\text { H. Görg } \\
\text { C. Montagna }\end{array}$ & $\begin{array}{l}\text { Should I Stay or Should I Go? A Note on } \\
\text { Employment Protection, Domestic Anchorage, } \\
\text { and FDI }\end{array}$ & 2 & $08 / 03$ \\
\hline 846 & $\begin{array}{l}\text { D. de la Croix } \\
\text { F. Docquier }\end{array}$ & $\begin{array}{l}\text { Diverging Patterns of Education Premium and } \\
\text { School Attendance in France and the US: A } \\
\text { Walrasian View }\end{array}$ & 6 & $08 / 03$ \\
\hline 847 & B. R. Chiswick & $\begin{array}{l}\text { Jacob Mincer, Experience and the Distribution of } \\
\text { Earnings }\end{array}$ & 1 & $08 / 03$ \\
\hline 848 & $\begin{array}{l}\text { A. Chevalier } \\
\text { G. Conlon }\end{array}$ & Does It Pay to Attend a Prestigious University? & 6 & $08 / 03$ \\
\hline 849 & W. Schnedler & Traits, Imitation, and Evolutionary Dynamics & 5 & $08 / 03$ \\
\hline 850 & $\begin{array}{l}\text { S. P. Jenkins } \\
\text { L. Osberg }\end{array}$ & $\begin{array}{l}\text { Nobody to Play with? The Implications of } \\
\text { Leisure Coordination }\end{array}$ & 5 & $08 / 03$ \\
\hline 851 & J. D. Angrist & $\begin{array}{l}\text { Treatment Effect Heterogeneity in Theory and } \\
\text { Practice }\end{array}$ & 6 & $08 / 03$ \\
\hline 852 & $\begin{array}{l}\text { A. Kugler } \\
\text { M. Kugler }\end{array}$ & $\begin{array}{l}\text { The Labor Market Effects of Payroll Taxes in a } \\
\text { Middle-Income Country: Evidence from } \\
\text { Colombia }\end{array}$ & 1 & $08 / 03$ \\
\hline 853 & $\begin{array}{l}\text { I. Ekeland } \\
\text { J. J. Heckman } \\
\text { L. Nesheim }\end{array}$ & Identification and Estimation of Hedonic Models & 6 & $08 / 03$ \\
\hline 854 & $\begin{array}{l}\text { A. Ferrer-i-Carbonell } \\
\text { B. M. S. Van Praag }\end{array}$ & Income Satisfaction Inequality and Its Causes & 3 & $08 / 03$ \\
\hline 855 & $\begin{array}{l}\text { B. Irlenbusch } \\
\text { D. Sliwka }\end{array}$ & $\begin{array}{l}\text { Career Concerns in a Simple Experimental } \\
\text { Labour Market }\end{array}$ & 1 & $08 / 03$ \\
\hline 856 & D. Sliwka & $\begin{array}{l}\text { Management Incentives, Signaling Effects and } \\
\text { the Costs of Vertical Integration }\end{array}$ & 1 & $08 / 03$ \\
\hline
\end{tabular}

An updated list of IZA Discussion Papers is available on the center's homepage www.iza.org. 